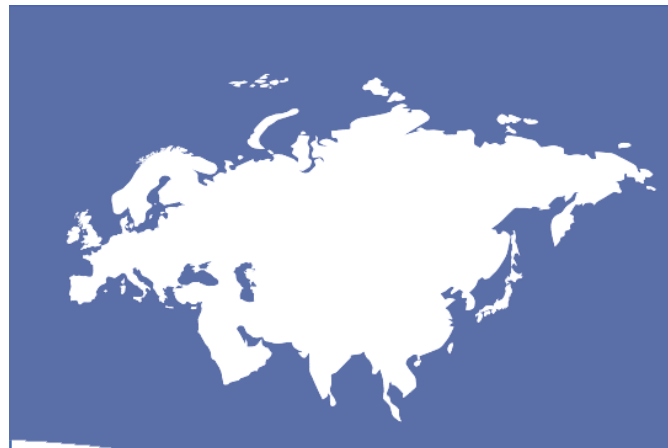

BOSNA-HERSEK'IN BÖLÜNMESI KONULU SLOVENYA BELGESI BUK-YTO-BONN YETKILERININ DEVAM ETTIRILMESININ GEREKLILIĞiNI TEYIT ETMEKTEDIR

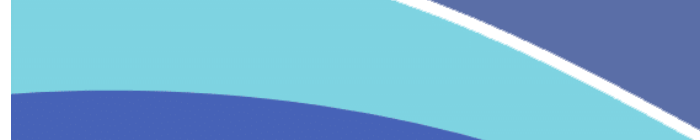

Analiz No : $2021 / 18$

Teoman Ertuğrul TULUN

\title{
10.05.2021
}

Bir süre önce yayınlamış olduğumuz Bosna-Hersekte Barışı Uygulama Konseyi ile Yüksek Temsilcilik Ofisi Neden Devam Etmelidir? başlıklı AViM analizimizde Barışı Uygulama Konseyinin (BUK) yetkilerinin, Bonn Yetkileri dahil olmak üzere, devam ettirilmesinin, anayasası çerçevesinde Bosna-Hersekin egemenliği ve toprak bütünlüğünün korunması için gerekli olduğu görüşünü savunmuştuk.[1] Bu bağlamda, BUK Yönlendirme Kurulunun bir üyesi olan Türkiyenin, Bosna-Hersek ile müstesna bağları olan bir Balkan ülkesi olarak, Yüksek Temsilcilik Ofisinin (YTO) devamı konusundaki kararların şekillendirilmesinde etkili olmak konusunda kabiliyeti ve sorumluluğu olduğunun altını çizmiştik. Ayrıca, Türkiyenin bu süreçte, geçmişte yapmış olduğu gibi, Bosna-Hersekin egemenliğini ve toprak bütünlüğünü sadakatle savunup, Bosna-Herseki bölme yaklaşımlarına güçlü bir biçimde karşı çıkması gerektiğini vurgulamıştık.

Daha analizimizin mürekkebi kurumadan, Slovenya Başbakanı Janez Janšanın Avrupa Birliği ( $A B$ ) Konseyi Başkanı Charles Michele Bosna-Hersekin sınırlarının yeniden çizilmesini teklif eden bir belge göndermiş olduğuna dair rahatsız edici haberlerle karşılaştık. Janez Janšanın AB Konseyi Başkanına, Yugoslavyanın nihai dağılışı konusunda yönlendirici ilkeleri içeren, Slovenyanın gelecek $A B$ dönem başkanlığı önceliklerine dair kamuoyundan gizlenmiş gayri-resmi belge (non-paper) tevdi ettiği basında kaydedilmiştir. Bahsi geçen basın haberleri ayrıca, Bosna-Hersek Cumhurbaşkanlığı Hırvat üyesi Željko Komšićin, yerel basına, Slovenya Cumhurbaşkanı Borut Pahorun 5 Mart 2021 tarihinde Bosna-Herseki resmi ziyareti esnasında gayri resmî bir görüşmede, Bosna-Hersek Cumhurbaşkanlığı üyeleri Milorad Dodik, Şefik Caferoviç ve Željko Komšiće benzer soruyu sormuş olduğunu teyit ettiğine dair ayrıntılı iddiaları da içermektedir. Haberlere göre, Komšić, Pahorun, Republika Srpska Oluşumuna (Entite) atıfla Bosna-Hersekte barışçıl ayrılmanın mümkün olup olmadığına dair bir soru sorduğunu belirtmiştir. Komšiće göre, bu soruya cevaben, kendisi ve Boşnak üye Caferoviç, bunun mümkün olmadığını belirtirken, Sırp üye Dodik bunun tersi bir yanıt vermiştir.[2] Basın haberlerine göre, hem Slovenya Cumhurbaşkanı 
hem de Başbakanı, Bosna-Hersekin dağılmasını veya sınırlarının yeniden çizilmesini savundukları iddialarını reddetmektedir.[3]

Söz konusu inkârlara rağmen, sözde belgenin ABye verilen kopyası, araştırmacı gazetecilik yapan bir Slovenya haber kaynağı olan necenzurirano.side yayınlanmıştır.[4] Söz konusu haber kaynağı, belgeyi herhangi bir sansüre tabi tutmadan yayınladığını iddia etmektedir. Batı Balkanlar[5] ૧૯İleriye dönük yol başlıklı belgenin, Şubat ayında Michelin özel kalem müdürlüğü tarafından teslim alındığı öne sürülmektedir. Belgenin yazarları bilinmemektedir. Bahse konu haber kaynağına göre, belge kesinlikle Slovenya Dışişleri Bakanlığında hazırlanmamıştır. İçeriğinin bir kısmının Budapeştede yazıldığı iddia edilmektedir. Bununla birlikte, Janšanın özel kalem müdürlüğünün belgenin farklı adreslere gönderilmesinde yer alması dolayısıyla, Brükseldeki diplomatik çevrelerde Slovenya belgesi olarak anılmaktadır.

Gayri-resmi belge, çözümler alt başlığı altında, Balkanlardaki sınırların değiştirilmesi konusunda son derece tehlikeli ve cüretkâr tavsiyeler içermektedir. Söz konusu tavsiyelerin tamamı kelimesine dokunulmadan aşağıda sunulmaktadır:

- Kosova ile Arnavutlukun birleştirilmesi. Kosovada nüfusun 95\%i, Arnavut ulusal kökenleriyle birleşmek istemektedir. Arnavutlukta benzer bir durum söz konusudur. Arnavutluk ile Kosova arasındaki sınır, fiiliyatta mevcut değildir. Kosovanın Sırp tarafına, özel statü verilecektir (Güney Tirol modeli takip edilerek).

- Republika Srpska topraklarının büyük bir bölümünün Sırbistan ile birleştirilmesi. Sırp ulusal meselesi, büyük ölçüde Republika Srpskanın büyük bir kısmının Sırbistan ile birleştirilmesiyle çözülebilir. Bu durumda Sırbistan, Kosovanın Arnavutluk ile birleşmesini kabul etmeye hazırdır.

- Hırvat ulusal meselesi, Bosna-Hersekteki Hırvat ağırlıklı kantonların Hırvatistan ile birleştirilmesiyle veya Bosna-Hersekin Hırvat bölgesine özel statü verilmesiyle çözülebilir (Güney Tirol modelinin metot olarak uygulanması suretiyle).

- Boşnaklar böylece bağımsız bir şekilde işleyen bir devlet ve onun sorumluluğunu elde edecektir. Halkın, AB ile birlikte veya AB olmayan (Türkiye) bir gelecek arasında tercih yapması için bir referandum düzenlenecektir. Şimdilik, Boşnakların tatmin edici çoğunluğu AB perspektifini savunmaktadır, ancak kargaşanın devam etmesi ve Türkiyenin ve radikal İslamın giderek artan etkileri neticesinde, durum önümüzdeki on yıllık süre içinde vahim bir biçimde kötüye gidebilir. (Koyu renk harfler eklenmiştir)

Gayrı-resmi belgenin Adımlar alt-başlığında, başka açıklamalarla beraber, aşağıdaki hususlara yer verilmektedir.

- Gizlilik içerisinde, planın uygulanması intimali, bölgedeki karar-vericiler ile ele alınacaktır (devam etmektedir)

- Gizliliğe riayet edilerek, planın desteklenmesi hususu, uluslararası toplumun karar vericileri ile ele alınacaktır (devam etmektedir)

- Eğer $A B, A B D$ ve bölgesel karar vericilerin çoğunluğu, planı ve uygulama adımlarını kabul ederlerse, $A B$, planın resmiyete dönüşmesi için harekete geçecektir. 
Yalnızca Balkanları değil, tüm Avrupayı savaş bataklığına sürükleme potansiyelini taşıyabilecek böylesine kötü niyetli bir planın Slovenya tarafından hazırlanmakta olduğu anlaşılmaktadır. Planın terminolojisi, planın yürürlüğe konulması için temasların gerçekleştirildiğini ortaya çıkarmaktadır. Belgede Türkiyeye yapılan atıflar, tamamen düşmanca bir nitelik taşımaktadır. Bosna-Hersek, Avrupa haritasından utanmazca silinmeye çalışılmaktadır. Müslüman Boşnaklar, küçük ve kuşatılmış bir toprağa hapsedilmeye kalkışılmaktadır. Kısacası plan, Müslümanlara ve Türklere karşı düşmanlığı yansıtmaktadır.

$A B$ bugüne dek raporun varlığını inkâr etmemiştir. Ancak, ABD, bu Slovenya-bağlantılı Bosna-Herseki bölme planını reddetmiştir. Bir ABD dışişleri bakanlığı sözcüsü, 15 Nisan 2021 tarihinde, Amerika Birleşik Devletleri, Bosna-Hersek ile eskiden beri süregelen ortaklığına samimi değer vermekte ve onun Dayton Barış Anlaşmasına dayanan egemenliğini ve toprak bütünlüğünü savunmaktadır. açıklamasında bulunmuştur.[6]

Böylesine kötü niyetli bir planın $A B$ bünyesinde hazırlanıp ele alınmış olması endişe vericidir. Ayrıca, AB başkanlığını üstlenecek olan bir NATO üyesinin isminin bu plan ile ilişkili olması ürkütücüdür. Türkiyenin Bosna-Hersekin egemenliği ve toprak bütünlüğünü, BUK Yönlendirme Kurulu dahil olmak üzere, her platformda desteklemeye devam edeceğine şüphe yoktur. Türkiyenin, BUK Yönlendirme Kurulu toplantılarında bu konuyu açmasının ve $A B$ temsilcilerinden açıklama talep etmesinin yararlı olacağına inanılmaktadır.

Slovenya bağlantılı gayri resmi belgeye ilişkin tartışma devam ederken, Balkanlarda sınır değişikliği konusunda titizlikle takip edilmesi gereken yeni iddialar ortaya atılmaktadır. Bu doğrultuda, haberlere göre, Kosova günlük gazetesi Koha Ditore, Kosova ile Sırbistanın birbirinin toprak bütünlüğünü, Almanya ve Fransa tarafından hazırlanan bir AB pazarlığıyla tanıyacağına dair iddialar yayınlamıştır.[7] Haberde, Ortodoks Sırpların imtiyazlı statüye sahip olacakları kuzey Kosova otonom bölgesinin oluşturulacağı ileri sürülmektedir. Buna karşılık, Sırbistan, Kosovanın uluslararası kuruluşlarda üyeliğini engellemeyecek, Kosova ise ticari engeller koymayacaktır. Kosovadaki Almanya ve Fransa Büyükelçilikleri, ülkelerinin söz konusu entrikaya müdahil olduklarını reddetmiştir. Kosovadaki Almanya Büyükelçisi, sosyal medyadan şu paylaşımda (tweet) bulunmuştur: Koha Ditore tarafından yayınlanan sözde Alman-Fransız gayri-resmi belgesi yalan haberdir! Bir belge söz konusu olabilir, ancak bu kesinlikle Alman-Fransız değildir. Avrupa Birliği Özel Temsilcisinin liderliğiyle, $A B$ öncülüğündeki diyaloğa tam desteğimiz mevcuttur.[8] i̇laveten, $A B$ Komisyonu da iddiaları ret etmiş ve sözde belge ABnin tutumunu yansıtmamakta olup, ne $A B$ Komisyonu, ne de $A B$ Dış illişkiler Servisi tarafından teslim alınmamıştır[9] açıklamasında bulunmuştur.

Bu açıklamalara ek olarak, haberlere göre NATO Genel Sekreteri Jens Stoltenberg, Kuzey Makedonya Cumhurbaşkanı Stevo Pendarovski ile Brükseldeki NATO karargahında yaptığı görüşmeden sonra basına, Slovenya tarafından hazırlandığı iddia edilen gayri-resmi belgeye dair bir açıklamada bulunmuştur. Adıgeçen yaptığı açıklamada, sınırların değişeceğine dair kurgular, belirsizlik ortamını güçlendirmekte ve bölgede istikrarsızlık riski yaratmaktadır[10] şeklinde ifadelerde bulunmuştur. Bu bağlamda, Kuzey Makedonya 
Cumhurbaşkanı Pendarovski, Balkanlarda sınırların değiştirilmesinin, bir kan gölüne yol açacağını vurgulamıştır. Pendarovski ayrıca, bu yazıları kaleme alanların isimlerini saklamayı tercih ettiklerini ve bunun, kendi fikirlerinden utandıklarının bir kanıtı olduğunu söylemiştir.[11]

Yukarıda özetlenen gelişmeler birlikte değerlendirildiğinde, Balkanlarda sınırlarının değiştirilerek istikrarın sağlanabileceğini varsayan fikrin test edilmeye çalışıldığı görülmektedir. Bazı AB ülkeleri tarafından zemin yoklandığı anlaşılmaktadır. Sınır değişiklikleri konusundaki sözde gayri-resmi belgeler basına sızdığı zaman, bu ülkelerin hiçbirisi sorumluluk almayıp, iddialı belgelerini yetim bırakmayı tercih etmiş ve gölge oyunu oynamışlardır.

Avrasya İncelemeleri Merkezi (AViM) olarak, bunun son derece tehlikeli bir oyun olduğunu vurgulamak isteriz. Balkanların ve Avrupanın hiç olmadığı kadar güvenlik ve istikrara intiyacı olduğu bir dönemden geçmekteyiz. Böylesi bir dönemde, itidal içinde hareket etmekte ve uluslararası toplumun çözmekte zorlandığı sorunların körüklenmesinden kaçınılmasında yarar görmekteyiz.

*Fotoğraf: necenzurirano.si

**Bu Analiz yazısının aslı ingilizce olarak kaleme alınmıştır. Makalenin tercümesi AViM Çevirmeni Ahmet Can Öktem tarafından yapılmıştır.

[1] Teoman Ertuğrul Tulun, Why Should The Role Of The Peace Implementation Council And OHR Continue In Bosnia And Herzegovina?, Center For Eurasian Studies (AVIM) 2021, sy 14 (06 Nisan 2021): 7.

[2] Zeljko Trkanjec, Slovenia Suspected of Seeking Peaceful Dissolution of BosniaHerzegovina, Euroactiv, 13 Nisan 2021, https://www.euractiv.com/section/enlargement/news/slovenia-suspected-of-seekingpeaceful-dissolution-of-bosnia-herzegovinal.

[3] Anja Vladisavljevic, Slovenian Leaders Deny Calling for Dissolution of Bosnia, Balkan Insight, 12 Nisan 2021, blm. News, https://balkaninsight.com/2021/04/12/slovenianleaders-deny-calling-for-dissolution-of-bosnia/.

[4] Primož Cirman ve Vesna Vuković, Objavljamo dokument o razdelitvi BiH, ki ga išče ves Balkan, necenzurirano.si, 15 Nisan 2021, blm. Aktualno, https://necenzurirano.si/clanek/aktualno/objavljamo-slovenski-dokument-o-razdelitvi-bih-kiga-isce-ves-balkan-865692. 
[5] AViM "Batı Balkanlar" terimini siyasi amaçlı ayrılıkçı terminoloji olarak görmekte ve bölge için coğrafi ve tarihi tanımlama olan "Balkanlar"ın kullanılmasına devam etmektedir.

[6] Andrew Rettman ve Ekrem Krasniqi, US Rejects Slovenia-Linked Plan to Break up Bosnia, EU Observer, 16 Nisan 2021, blm. EU \& The World, https://euobserver.com/world/151572.

[7] Matthew Holroyd ve Milos Milic, EU, France and Germany Play down Serbia-Kosovo Deal Reports, Euronews, 28 Nisan 2021, blm. Wold, https://www.euronews.com/2021/04/28/eu-france-and-germany-play-down-serbia-kosovodeal-reports.

[8] EWB, Another Alleged Non-Paper Proposes the Conclusion of Kosovo-Serbia Normalisation Process by 2022, European Western Balkans, 297April 2021, blm. Politics, https://europeanwesternbalkans.com/2021/04/27/another-alleged-non-paper-proposes-theconclusion-of-kosovo-serbia-normalisation-process-by-20221.

[9] Holroyd ve Milic, EU, France and Germany Play down Serbia-Kosovo Deal Reports.

[10] Ömer Tuğrul Çam, NATO: Balkanlarda sınır değişikliğiyle ilgili spekülasyonlar istikrarı bozar, Anadolu Haber Ajansı, 28 Nisan 2021, blm. Dünya, https://www.aa.com.tr/tr/dunya/nato-balkanlarda-sinir-degisikligiyle-ilgili-spekulasyonlaristikrari-bozar/2223362\#.

[11] Kuzey Makedonya Cumhurbaşkanı: Balkanlarda Sınırlar Değiştirilirse Ortalık Kan Gölü Olur, Euronews, 28 Nisan 2021, blm. Dünya, https://tr.euronews.com/2021/04/28/kuzeymakedonya-cumhurbaskan-balkanlarda-s-n-rlar-degistirilirse-ortal-k-kan-golu-olur.

Yazar Hakkında :

Teoman Ertuğrul Tulun , Avrasya Incelemeleri Merkezi'nde (Ankara) analisttir. Bilkent Üniversitesi'nde Siyaset Bilimi ve Kamu Yönetimi Bölümünde doktora adayıdır. Avrupa Birliği Çalışmaları, Toplumsal Hareketler, Irkçılık ve Nefret Söylemi Çalışmaları ve Devlet İnşaası alanlarında çalışmalar yapmaktadır.

Atıfta bulunmak için: TULUN, Teoman Ertuğrul. 2021. "BOSNA-HERSEK'IN BÖLÜNMESi KONULU SLOVENYA BELGESI BUK-YTO-BONN YETKILERININ DEVAM ETTIRILMESININ GEREKLILIĞINI TEYIT ETMEKTEDiR." Avrasya Incelemeleri Merkezi (AViM), Analiz No.2021 / 18. Mayıs 10. Erişim Ekim 22, 
2021. https://avim.org.tr/tr/Analiz/BOSNA-HERSEK-IN-BOLUNMESI-KONULU-SLOVENYA-BELGESI-BUK-

YTO-BONN-YETKILERININ-DEVAM-ETTIRILMESININ-GEREKLILIGINI-TEYIT-ETMEKTEDIR

\section{(2) AVIM}

Süleyman Nazif Sok. No: 12/B Daire 3-4 06550 Çankaya-ANKARA / TÜRKIYE

Tel: +90 (312) 43850 23-24 • Fax: +90 (312) 4385026

@avimorgtr

7 https://www.facebook.com/avrasyaincelemelerimerkezi

E-Posta: info@avim.org.tr

http://avim.org.tr

(c) 2009-2021 Avrasya Incelemeleri Merkezi (AViM) Tüm Hakları Saklıdır 